\title{
The Efficacy of Short-Duration Polyethylene Glycol plus Electrolytes for Improving Bowel Preparation of Colonoscopy in Patients with Chronic Constipation
}

\author{
Naohisa Yoshida $\left(D,{ }^{1}\right.$ Yoshikazu Inagaki, ${ }^{2}$ Kohei Fukumoto, ${ }^{3}$ Hiroyuki Yoriki, ${ }^{4}$ \\ Yutaka Inada, ${ }^{5}$ Takaaki Murakami, ${ }^{6}$ Yuri Tomita, ${ }^{1}$ Hikaru Hashimoto, ${ }^{1}$ Satoshi Sugino, ${ }^{1}$ \\ Ryohei Hirose, ${ }^{1}$ Osamu Dohi, ${ }^{1}$ Ken Inoue, ${ }^{1}$ and Yoshito Itoh ${ }^{1}$ \\ ${ }^{1}$ Department of Molecular Gastroenterology and Hepatology, Kyoto Prefectural University of Medicine, Graduate School of \\ Medical Science, Kyoto, Japan \\ ${ }^{2}$ Department of Gastroenterology, Nishijin Hospital, Kyoto, Japan \\ ${ }^{3}$ Department of Gastroenterology, Nara City Hospital, Nara, Japan \\ ${ }^{4}$ Department of Gastroenterology, Otsu City Hospital, Shiga, Japan \\ ${ }^{5}$ Department of Gastroenterology, Kyoto First Red Cross Hospital, Kyoto, Japan \\ ${ }^{6}$ Department of Gastroenterology, Aiseikai Yamashina Hospital, Kyoto, Japan
}

Correspondence should be addressed to Naohisa Yoshida; naohisa@koto.kpu-m.ac.jp

Received 19 September 2020; Revised 2 November 2020; Accepted 11 November 2020; Published 24 November 2020

Academic Editor: Gian Luigi Adani

Copyright (C) 2020 Naohisa Yoshida et al. This is an open access article distributed under the Creative Commons Attribution License, which permits unrestricted use, distribution, and reproduction in any medium, provided the original work is properly cited.

\begin{abstract}
Backgrounds and Aims. Sachets of polyethylene glycol plus electrolytes (PEG+E: Movicol: EA Pharma, Tokyo, Japan) are used for chronic constipation, and its efficacy is reported only for female and nonelderly people. Chronic constipation is one of the reasons of poor colonoscopic bowel preparation (BP). We analyzed its efficacy in improving chronic constipation and poor colonoscopic BP related to it, including male and elderly people. Materials and Methods. This multicenter retrospective study was conducted from September 2019 to September 2020 at 5 related institutions among patients $\geq 20$ years old diagnosed with chronic constipation whose previous colonoscopic BP had had a fair or poor Aronchick score. Two or four sachets of PEG+E (13.7 or $27.4 \mathrm{~g} / \mathrm{day})$ were prescribed for 1 week before colonoscopy. We analyzed the rate of improvement in BP, effect-related factors, spontaneous bowel movements (SBMs), stool consistency, improvement of constipation symptoms, and adverse events. Results. We evaluated 106 cases (56 males) with an average age of $69.5 \pm 9.4$ years old ( $\leq 74$ years old: 68 cases, $\geq 75$ years old: 38 cases). The improvement rate of $\mathrm{BP}$ was $72.6 \%$, and the insertion time and pain score also improved. A performance status of 1 or 2 was associated with poor BP. SBMs (times/week) increased from $4.0 \pm 1.9$ to $6.1 \pm 2.6(p<0.001)$. The overall improvement rates of SBMs, stool consistency, symptoms of constipation, and rate of adverse events were $58.5 \%, 90.6 \%, 59.4 \%$, and $6.6 \%$, respectively, showing no significant differences with regard to age or gender. Conclusions. Short-duration PEG+E was effective for improving poor BP and chronic constipation.
\end{abstract}

\section{Introduction}

Colonoscopy is widely performed for screening, surveillance after polyp and cancer resection, various abdominal complaints, and removal of polyps and cancers. Resection of polyps is reported to lead to a reduction in colorectal cancer death [1]. However, up to $30 \%$ of colonoscopies have poor bowel preparation (BP), which leads to decreased lesion detection due to poor visualization and an increased need for repeat colonoscopies $[2,3]$. An older age, male sex, inpatient status, diabetes mellitus, constipation, and tricyclic antidepressant use are known to be associated with inadequate BP [4]. In particular, constipation increases the risk of inadequate BP about twofold $[5,6]$. For cases with these risk 
factors, we regularly strengthen the method of BP, such as increasing the amount of polyethylene glycol (PEG), adding a laxative before the procedure, and performing strict diet limitation [7]. Regarding the addition of a laxative, bisacodyl, sennoside, picosulfate sodium, magnesium oxide, and shortduration PEG are prescribed in clinical practice. However, no evidence concerning the efficacy of these additional laxatives for this purpose has yet been obtained.

In Japan, magnesium oxide and anthraquinolone stimulant laxatives (e.g., sennoside) have been widely used for chronic constipation. The guideline for the medical treatment of constipation set by the American College of Gastroenterology proposes lifestyle habit guidance and the administration of osmotic laxatives [8-10]. In 2018, sachets of an osmotic laxative of PEG4000 plus electrolytes (PEG +E: Movicol: EA Pharma, Tokyo, Japan) were launched for chronic constipation in Japan, and the recent Japanese guideline now recommends this drug instead of anthraquinolone stimulant laxatives [11]. It is minimally absorbed and increases the water content of stool in a dose-dependent manner. Previous reports about the efficacy of this drug are limited for nonelderly people and female [12-14].

In the present study, we analyzed the efficacy of shortduration $\mathrm{PEG}+\mathrm{E}$ for chronic constipation and improving poor BP for colonoscopy in patients with chronic constipation, including male gender and elderly people.

\section{Patients and Methods}

This was a multicenter, single-arm, retrospective cohort study. We reviewed 118 patients from 5 related institutions diagnosed from September 2019 to September 2020 with chronic constipation whose previous colonoscopic BP had been fair or poor on the Aronchick bowel preparation scale [15]. The related institutions were Kyoto Prefectural University of Medicine, Nishijin Hospital, Otsu City Hospital, Nara City Hospital, and Aiseikai Yamashina Hospital.

The inclusion criteria were patients $\geq 20$ years old suffering from $\geq 2$ of the following 6 criteria of chronic constipation under the Rome IV standard: straining, hard stool, residual stool feeling, occlusion feeling, manual bowel movement (BM) performed $\geq 25 \%$ of overall BMs, and BM frequency $<3$ times a week [16]. A chronic status was defined as symptoms being present for at least six months, with the symptoms described above being present for at least three months. The diagnosis of chronic constipation was made by each doctor in each institution, and the study representative endoscopist (N.Y.) reconfirmed whether or not the definition had been met in each case. We excluded patients with fatal cardiopulmonary, hepatic, or renal disease. We excluded cases with $\geq 7$ BMs/week who met the definition of chronic constipation because these cases might have had irritable bowel syndrome. Short-duration PEG+E (6.8 g/sachet) at $13.7 \mathrm{~g} /$ day was prescribed initially 1 week before colonoscopy. The PEG+E was dissolved in $125 \mathrm{~mL}$ of water. After 2 days' intake, the amount of PEG could be increased to $27.4 \mathrm{~g}$ according to the stool frequency and consistency.

The evaluation items for this study were the patients' characteristics, improvement in colonoscopic BP after PEG
$+\mathrm{E}$, and efficacy of $\mathrm{PEG}+\mathrm{E}$ for chronic constipation. The improvement in the BP was defined as an increase of at least 1 score in the Aronchick score. We divided all cases into improved and nonimproved BP groups and analyzed the colonoscopic status and effect-related factors among patient characteristics as well as the underlying disease and concomitant medications. The colonoscopic status included the rate of cecal intubation, insertion time, and pain score. The pain score was scored as 0 (no pain), 1 (mild pain), 2 (moderate pain), or 3 (severe pain) by each operator. Regarding the efficacy of $\mathrm{PEG}+\mathrm{E}$ for chronic constipation, we analyzed the number of spontaneous BMs (SBMs) 1 week before and after the administration of $\mathrm{PEG}+\mathrm{E}$ according to the number of previous BMs (<3/week or 3-6/week), gender (male or female), and age ( $\leq 74$ or $\geq 75$ years old). The number of SBMs referred to BMs that occurred without a laxative/enema or manual evacuation. The improvement rate for SBM was also calculated according to the number of previous BMs, gender, and age and defined as an increase in $\geq 1$ BM per week from the baseline with $\geq 3 \mathrm{BMs}$ /week, in reference to a previous report [17].

The changes in stool consistency according to the Bristol stool form scale (BSFS) were also analyzed according to previous number of BMs, gender, and age [18]. The BSFS is a global standard for the evaluation of the stool shape (range of 1 to 7 ). Types 1 and 2 are hard stools, types 3-5 are normal stools, and types 6 and 7 are loose stools. With respect to the stool consistency, an "increase to types 3-5" was considered as a sign of improvement. The improvement rate of constipation symptoms, such as straining, residual stool feeling, and occlusion feeling, was also analyzed. The time until the first SBM after the administration of PEG within $48 \mathrm{~h}$ and the rate of SBM within $24 \mathrm{~h}$ were also analyzed. Adverse events were examined according to the previous number of BMs, gender, and age.

With respect to colonoscopic BP, we used highly concentrated PEG (MOVIPREP; EA Pharma, Tokyo, Japan) according to our previous report [19]. In brief, patients received a low residual diet on the day before colonoscopy and consumed $10 \mathrm{~mL}$ of picosulfate sodium at 9-10 PM that same day. Patients then took 1.0 L of highly concentrated PEG and $0.5 \mathrm{~L}$ of water $3 \mathrm{~h}$ prior to the examination on the day of colonoscopy. All colonoscopies were performed by 5 veteran endoscopists who had experience performing more than 5,000 colonoscopies.

We obtained informed consent from all patients before the colonoscopy. This study was retrospective in setting, and an opt-out about the study to the patients was performed in the representative facility (Nishijin Hospital). This research was approved by the Ethics Committee of Nishijin Hospital (Number 20-05, approved data: May 14, 2020) and Kyoto Prefectural University of Medicine (ERB-C1600, approved data: Dec. 23, 2019) and was in accordance with the World Medical Association Declaration of Helsinki.

2.1. Statistical Analyses. The Mann-Whitney $U$ test, chisquared test, and Yates continuity correction were used in this study. To compare continuous variables, the MannWhitney $U$ test was used. Categorized variables were 


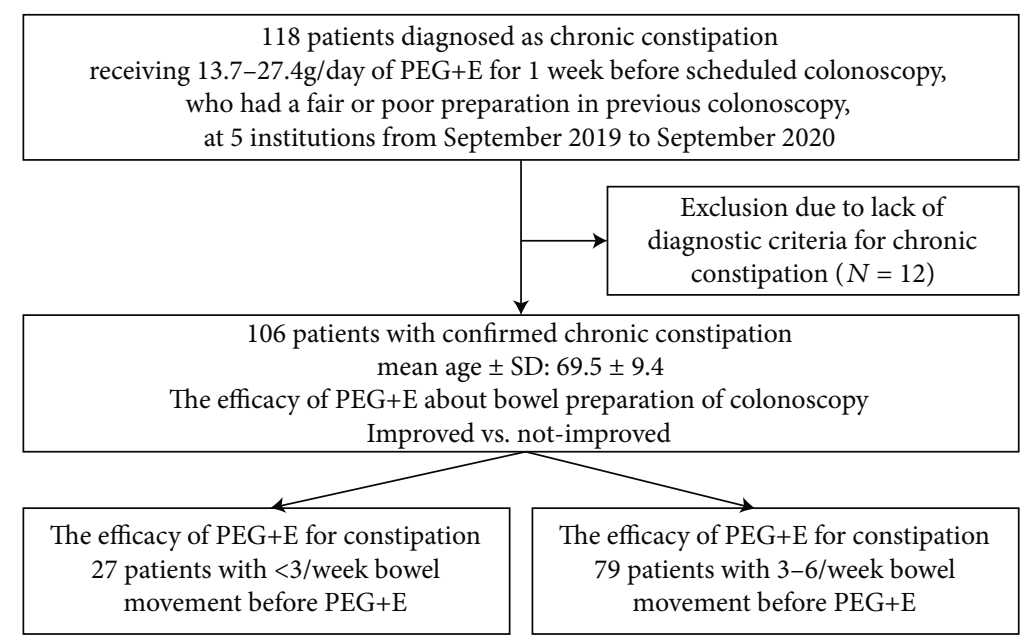

Figure 1: A flow diagram of the present study. PEG+E: polyethylene glycol plus electrolytes; SD: standard deviation.

analyzed by the chi-square test and Yates continuity correction. All statistical analyses were performed using the SPSS software program (IBM Japan, Ltd., Tokyo, Japan). $p<0.05$ was considered significant for all statistical analyses.

\section{Results}

After excluding 12 cases that did not meet the diagnostic criteria for chronic constipation, we finally analyzed 106 cases with chronic constipation to determine the improvement in $\mathrm{BP}$ and chronic constipation (Figure 1). The gender was male in $56(52.8 \%)$ and female in $50(47.2 \%)$ with an average age of $69.5 \pm 9.4$ years old. Regarding the age distribution, 38 cases $(35.8 \%)$ were $\geq 75$ years old (Table 1$)$. Thirty-five cases (33.0\%) had used other laxatives. The final dose of PEG+E was $13.7 \mathrm{~g} /$ day for 94 cases $(88.7 \%)$ and $27.4 \mathrm{~g} /$ day for 12 cases $(11.3 \%)$. With respect to the definition of chronic constipation, 27 cases (25.5\%) had <3 BMs/week, 60 cases (56.6\%) had hard stool (Bristol bowel consistency scale 1 or 2 ), and 99 cases (93.4\%) had other symptoms of constipation according to the Rome IV criteria, such as straining, residual stool feeling, and occlusion feeling.

With respect to the improvement rate in the frequency of SBMs, 77 cases showed efficacy (72.6\%), with their score improving by 1 to 2 scores (improvement of 2 scores in 18 cases, improvement of 1 score in 59 cases; Figure 2). The rate of excellent+good was $69.8 \%$.

A comparison between the improved BP and the nonimproved BP group was made (Table 2). There were no significant differences with respect to the gender, age, body mass index, concomitant use of laxatives, dose of PEG, presence of various underlying diseases, and use of concomitant drugs. The rate of a poor performance status (scale $1+2$ ) was higher in the non-improved BP group than in the improved BP group $(27.6 \%$ vs. $7.8 \%, p=0.01)$. Regarding colonoscopy, the insertion time (min, mean \pm standard deviation (SD)) was shorter in the improved BP group than in the nonimproved BP group $(8.3 \pm 6.4$ vs. $9.2 \pm 7.5, p=0.03)$. The pain score (mean $\pm \mathrm{SD}$ ) was also better in the improved $\mathrm{BP}$ group than in the non-improved $\mathrm{BP}$ group $(0.4 \pm 0.8$ vs. $0.6 \pm 0.9, p=0.02$ ).

The frequency of SBMs (times/week, average \pm SD) in the week after $\mathrm{PEG}+\mathrm{E}$ administration significantly improved compared with that before its administration (6.1 \pm 1.8 vs. $4.0 \pm 1.8, p<0.001$ ) (Figure 3). The frequency of SBM (times/week) increased from $1.7 \pm 0.5$ to $4.4 \pm 2.9$ in 27 cases with $<3$ SBMs/week $(p<0.001)$ and from $4.7 \pm 1.4$ to $6.7 \pm 2.6$ times/week in 79 cases with 3-6 SBMs/week $(p=0.03)$.

The improvement rates of SBMs/week, stool consistency, and constipation symptoms were $58.5 \%$ (62 cases), $90.6 \%$ (96 cases), and 59.4\% (63 cases), respectively (Table 3). The improvement rates of SBMs/week in cases with $<3$ BMs/week and 3-6 BMs/week were $77.8 \%$ and $51.9 \%$, respectively $(p=0.01)$. There were no significant differences in these rates, regardless of gender and age.

The mean time to first SBM within $48 \mathrm{~h}$ after taking PEG $+\mathrm{E}$ was $25.7 \pm 10.1 \mathrm{~h}$ (Table 4 ). This time was significantly longer for those with $<3 \mathrm{BMs}$ /week than for those with 3-6 BMs/week $(29.7 \pm 13.0$ vs. $24.6 \pm 9.0, p=0.01)$. Regarding gender and age, there were no significant differences in this time. The SBM rate within $24 \mathrm{~h}$ after taking $\mathrm{PEG}+\mathrm{E}$ was $82.1 \%$ (87 cases); it was $69.6 \%$ for those with $<3$ BMs/week and $89.9 \%$ for those with 3-6 BMs/week $(p=0.03)$. Regarding gender and age, there were no significant differences in the rate.

Adverse events were observed in 7 cases (6.6\%), as follows: 2 cases $(1.9 \%)$ of abdominal pain, 2 cases $(1.9 \%)$ of increase residual stool feeling, 1 case $(0.9 \%)$ of diarrhea, 1 case $(0.9 \%)$ of abdominal distension, and 1 case $(0.9 \%)$ of abdominal discomfort (Table 5). Regarding the number of BMs before prescription of PEG-E, gender, and age, the rates of adverse events were $7.4 \%$ (2 cases: 1 abdominal pain and 1 diarrhea) in those with $<3 \mathrm{BMs} /$ week and $6.3 \%$ (5 cases: 1 abdominal pain, 2 increase of residual stool feeling, 1 abdominal distension, and 1 abdominal discomfort) in those with 3$6 \mathrm{BMs} /$ week $(p=0.94), 7.1 \%$ (4 cases: 2 increase residual stool feeling, 1 abdominal distention, and 1 abdominal 
TABLe 1: Patients' characteristics.

\begin{tabular}{|c|c|}
\hline & 106 \\
\hline Gender, $n(\%)$; male : female & $56: 50(52.8: 47.2)$ \\
\hline Age, mean \pm SD & $69.5 \pm 9.4$ \\
\hline Age distribution, $n(\%) \leq 74: \geq 75$ years old & $68: 38(64.2: 35.8)$ \\
\hline Body mass index, mean \pm SD & $23.3 \pm 3.9$ \\
\hline Performance status $(0: 1: 2), n(\%)$ & $92: 10: 4(88.8: 9.3: 1.9)$ \\
\hline Prescription of laxative, $n(\%)$ & $35(33.0)$ \\
\hline Prescription of irritant laxative, $n(\%)$ & $23(21.7)$ \\
\hline $\begin{array}{l}\text { Dose of PEG-E/day, } n(\%) \\
13.7 \mathrm{~g}: 27.4 \mathrm{~g}\end{array}$ & $94: 12(88.7: 11.3)$ \\
\hline \multicolumn{2}{|l|}{ Definition of chronic constipation } \\
\hline$<3 \mathrm{BMs}$ & $27(25.5)$ \\
\hline Bristol bowel consistency scale 1 and 2 & $60(56.6)$ \\
\hline Symptoms besides BM and bowel consistency & $99(93.4)$ \\
\hline \multicolumn{2}{|l|}{ Underlying disease } \\
\hline Hyperlipidemia, $n$ (\%) & $32(30.2)$ \\
\hline Colorectal surgery, $n(\%)$ & $16(15.1)$ \\
\hline Diabetes, $n(\%)$ & $13(11.2)$ \\
\hline Hypothyroidism, $n$ (\%) & $5(5.6)$ \\
\hline Hepatic or biliary disorder, $n(\%)$ & $4(3.7)$ \\
\hline Parkinson's disease, $n(\%)$ & $1(0.9)$ \\
\hline \multicolumn{2}{|l|}{ Concomitant medication } \\
\hline Antacids, $n(\%)$ & $28(23.4)$ \\
\hline Calcium antagonists, $n(\%)$ & $28(23.4)$ \\
\hline Antidepressants, $n(\%)$ & $14(7.5)$ \\
\hline Opioids, $n(\%)$ & $0(0.0)$ \\
\hline
\end{tabular}

SD: standard deviation; PEG+E: polyethylene glycol plus electrolytes; BM: bowel movement.

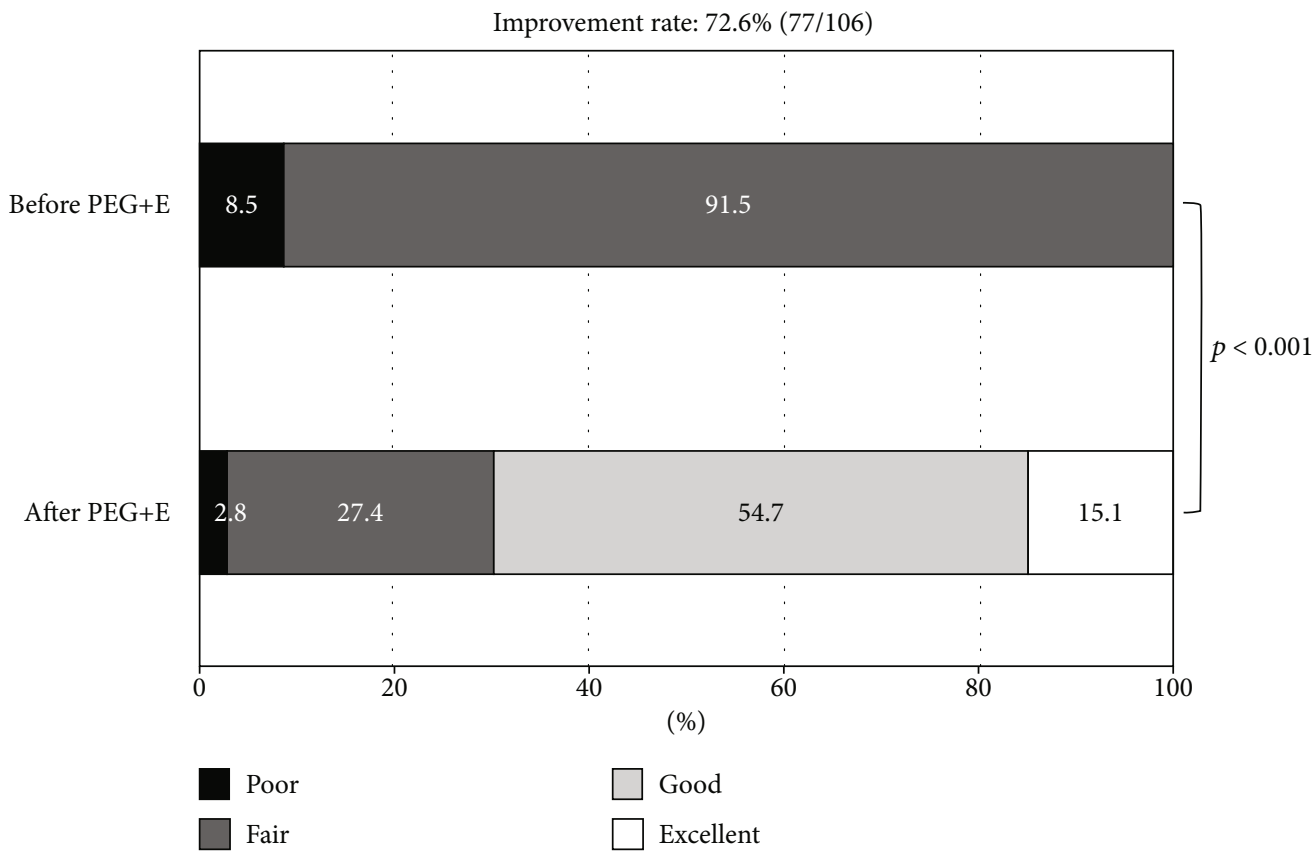

FIGURE 2: Improvement rate of bowel preparation after prescription of short-duration PEG+E. PEG+E: polyethylene glycol plus electrolytes. 
TABLE 2: The comparison between cases with and without improvement of bowel preparation.

\begin{tabular}{|c|c|c|c|}
\hline & Improved BP & Non-improved BP & $p$ value \\
\hline Case number & $77(72.6)$ & $29(27.4)$ & \\
\hline Gender, $n(\%)$, male : female & $40: 37(51.9: 48.1)$ & $16: 13(55.2: 44.8)$ & 0.77 \\
\hline Age, mean $\pm S D$ & $68.7 \pm 9.8$ & $71.6 \pm 8.6$ & 0.08 \\
\hline Age, $n(\%), \leq 74: \geq 75$ years old & $50: 27(64.9: 35.1)$ & $18: 11(62.1: 37.9)$ & 0.94 \\
\hline Body mass index, mean \pm SD & $23.2 \pm 3.8$ & $23.6 \pm 4.2$ & 0.36 \\
\hline Performance status $(0: 1+2), n(\%)$ & $71: 6(92.2: 7.8)$ & $21: 8(72.4: 27.6)$ & 0.01 \\
\hline $\begin{array}{l}\text { Laxative combination, } n(\%) \\
\text { Irritant laxative, } n(\%)\end{array}$ & $\begin{array}{l}25(32.5) \\
14(18.2)\end{array}$ & $\begin{array}{c}10(44.4) \\
9(29.6)\end{array}$ & $\begin{array}{l}0.84 \\
0.15\end{array}$ \\
\hline Dose of PEG/day (13.7 g:27.4 g), $n$ (\%) & $68: 9(88.3: 11.7)$ & $26: 3(89.7: 10.3)$ & 0.88 \\
\hline \multicolumn{4}{|l|}{ Colonoscopy } \\
\hline Cecal intubation, $n(\%)$ & $77(100)$ & $29(100)$ & 1.0 \\
\hline Insertion time $(\mathrm{min})$, mean $\pm \mathrm{SD}$ & $8.3 \pm 6.4$ & $9.2 \pm 7.5$ & 0.03 \\
\hline Pain score*, mean \pm SD & $0.4 \pm 0.8$ & $0.6 \pm 0.9$ & 0.02 \\
\hline \multicolumn{4}{|l|}{ Underlying disease } \\
\hline Hyperlipidemia, $n(\%)$ & $23(29.9)$ & $9(31.0)$ & 0.90 \\
\hline Colorectal surgery, $n(\%)$ & $14(18.2)$ & $2(6.9)$ & 0.25 \\
\hline Diabetes & $10(13.0)$ & $3(10.3)$ & 0.97 \\
\hline Hypothyroidism & $4(5.2)$ & $1(3.4)$ & 0.89 \\
\hline Hepatic or biliary disorder & $4(5.2)$ & $0(0.0)$ & 0.49 \\
\hline Parkinson's disease & $0(0.0)$ & $1(3.4)$ & 0.60 \\
\hline \multicolumn{4}{|l|}{ Concomitant medication } \\
\hline Antacids, $n(\%)$ & $20(26.0)$ & $8(27.6)$ & 0.86 \\
\hline Calcium antagonists, $n(\%)$ & $21(27.3)$ & $7(24.1)$ & 0.74 \\
\hline Antidepressants, $n(\%)$ & $8(10.4)$ & $6(20.7)$ & 0.28 \\
\hline
\end{tabular}

BP: bowel preparation; SD: standard deviation; PEG+E: polyethylene glycol plus electrolytes; pain score (0: no pain, 1: minimum pain, 2: moderate pain, and 3: severe pain).

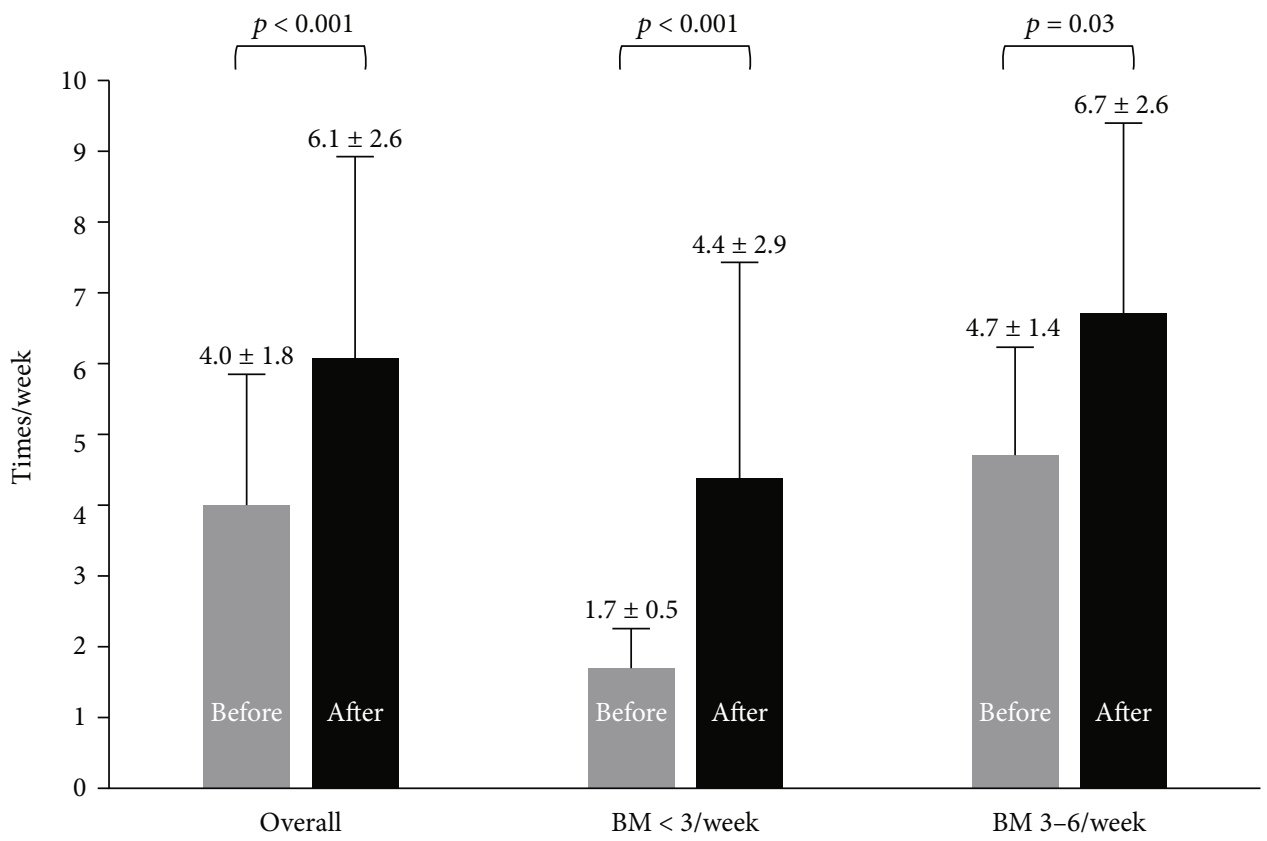

Figure 3: Changes of spontaneous bowel movements before and after short-duration PEG+E both for those with $<3$ BMs/week and 3-6 $\mathrm{BMs} /$ week. PEG+E: polyethylene glycol plus electrolytes; BM: spontaneous bowel movement. 
TABLE 3: Improvement of SBMs, stool consistency, and constipation symptoms in number of BMs/week, gender, and age.

\begin{tabular}{|c|c|c|c|c|c|c|c|}
\hline & Case number & $\begin{array}{c}\text { Improvement rate } \\
\text { of SBMs/week }\end{array}$ & $p$ value & $\begin{array}{l}\text { Improvement rate of } \\
\text { stool consistency }\end{array}$ & $p$ value & $\begin{array}{c}\text { Improvement rate of } \\
\text { constipation symptoms }\end{array}$ & $p$ value \\
\hline Overall, $n(\%)$ & 106 & $62(58.5)$ & & $96(90.6)$ & & $63(59.4)$ & \\
\hline$<3 \mathrm{BMs} /$ week, $n(\%)$ & 27 & $21(77.8)$ & 0.01 & $24(88.9)$ & 0.72 & $12(44.4)$ & 0.06 \\
\hline 3-6 BMs/week, $n$ (\%) & 79 & $41(51.9)$ & & $72(91.1)$ & & $51(64.6)$ & \\
\hline Male, $n(\%)$ & 56 & $30(53.6)$ & 0.27 & $50(89.3)$ & 0.63 & $33(58.9)$ & 0.91 \\
\hline Female, $n(\%)$ & 50 & $32(64.0)$ & & $46(92.0)$ & & $30(60.0)$ & \\
\hline$\leq 74$ years old, $n(\%)$ & 68 & $37(54.4)$ & 0.25 & $60(88.2)$ & 0.27 & $43(63.2)$ & 0.28 \\
\hline$\geq 75$ years old, $n(\%)$ & 38 & $25(65.8)$ & & $36(94.7)$ & & $20(52.6)$ & \\
\hline
\end{tabular}

SBM: spontaneous bowel movement; BM: bowel movement.

TABLE 4: Time to first SBMs and rate of SBMs within $24 \mathrm{~h}$ after prescription of short-duration PEG+E.

\begin{tabular}{lccc}
\hline & $\begin{array}{c}\text { Time to first spontaneous } \\
\text { BMs within } 48 \mathrm{~h} \text {, mean } \pm \text { SD }(n)\end{array}$ & $p$ value & $\begin{array}{c}\text { Rate of spontaneous } \\
\text { BMs within } 24 \mathrm{~h}, \%(n)\end{array}$ \\
\hline Overall & $25.7 \pm 10.1(102)$ & & $82.1(87)$ \\
$<3 \mathrm{BMs} /$ week & $29.7 \pm 13.0(23)$ & 0.01 & $69.6(16)$ \\
3-6 BMs/week & $24.6 \pm 9.0(79)$ & 0.40 & $89.9(71)$ \\
Male & $26.0 \pm 10.0(54)$ & & $85.2(46)$ \\
Female & $25.5 \pm 10.3(48)$ & 0.21 & $85.4(41)$ \\
$\leq 74$ years old & $26.3 \pm 10.5(66)$ & & $80.1(55)$ \\
$\geq 75$ years old & $24.6 \pm 9.4(36)$ & $84.2(32)$
\end{tabular}

SBM: spontaneous bowel movement; PEG+E: polyethylene glycol plus electrolytes; SD: standard deviation; BM: bowel movement.

discomfort) in males and 6.0\% (3 cases: 2 abdominal pain and 1 diarrhea) in females $(p=0.87)$, and $8.8 \%$ (6 cases, 1 abdominal pain, 2 increase residual stool feeling, 1 diarrhea, 1 abdominal distension, and 1 abdominal discomfort) in those $\leq 74$ years old and $2.6 \%$ ( 1 case: 1 abdominal pain) in those $\geq 75$ years old $(p=0.21)$.

\section{Discussion}

In this study, we showed a $72.6 \%$ improvement rate for poor colonoscopic BP using short-duration prescription of PEG $+E$, an efficacy that was achieved regardless of gender, age, underlying diseases, and concomitant prescription, including laxatives-but not a poor performance status. This is the first report describing the efficacy of additional daily PEG+E prior to colonoscopy for improving poor colonoscopic BP. Additional treatments typically given on the day of colonoscopy for poor BP can be slightly invasive, such as an enema or increase in cleansing solution. Instead of these treatments, we suggest daily short-duration $\mathrm{PEG}+\mathrm{E}$ as a less-invasive approach. In addition, this improvement in BP resulted in a shorter insertion time and lower pain score, and improved $\mathrm{BP}$ is also reported to yield an increase of adenoma detection rate and decrease in missed polyps [3].

Previous studies have described the efficacy of PEG for chronic constipation [17-21]. In a randomized control trial (RCT) comparing PEG3350+E to placebo from the UK, the number of cases in the PEG3350+E group, their mean age, and the rate of female gender were 68 cases, $43.6 \pm 14.9$ years old, and $85.1 \%$, respectively. The number of SBMs/week in the PEG group taking PEG for 4 weeks was $4.40 \pm 2.58$ compared to $3.11 \pm 1.93$ in the placebo group $(p<0.00001)$ [17]. A recent Japanese RCT using the same dose of PEG3350+E as our study involved 80 patients taking $\mathrm{PEG}+\mathrm{E}$, with a mean age of $44.3 \pm 11.6$ years old and $88.8 \%$ females [18]. The baseline number of SBMs/week was $1.6 \pm 0.9$, which increased during the first and second week of PEG3350+E prescription to 3.36 (95\% confidence interval (CI): 2.81$3.92)$ and 4.27 (95\% CI: 3.36-4.92), respectively, with responder rates of $80.0 \%$ and $86.3 \%$, respectively. These two studies could not include enough elderly people and male gender. In our study, the mean age and the rate of females were $69.5 \pm 9.4$ and $47.2 \%$ so that we could show the efficacy of $\mathrm{PEG}+\mathrm{E}$ for elderly people and male gender. In addition, the overall baseline number of SBMs/week $(4.0 \pm 1.8)$ was higher than in the present study; although, the overall improvement rate of SBM (58.5\%) was lower. However, the baseline number of SBMs/week, SBMs/week after PEG+E, and improvement rate of SBM in patients with $<3 \mathrm{BMs} /$ week in the present study were $1.7 \pm 0.5,4.4 \pm 2.9$, and $77.8 \%$, respectively, and these results were comparable to those of the two previous studies. We suggested our study included more moderate cases than the previous studies, suggesting that $\mathrm{PEG}+\mathrm{E}$ might be less effective for increasing SBM in patients with moderate constipation than severe constipation. In addition, our study included more males than the previous studies, and the efficacy of PEG+E for males seemed slightly lower than that for females.

Regarding stool consistency, in the previous study, the rates of improvement in stool consistency (BSFS 3, 4, and 5) 


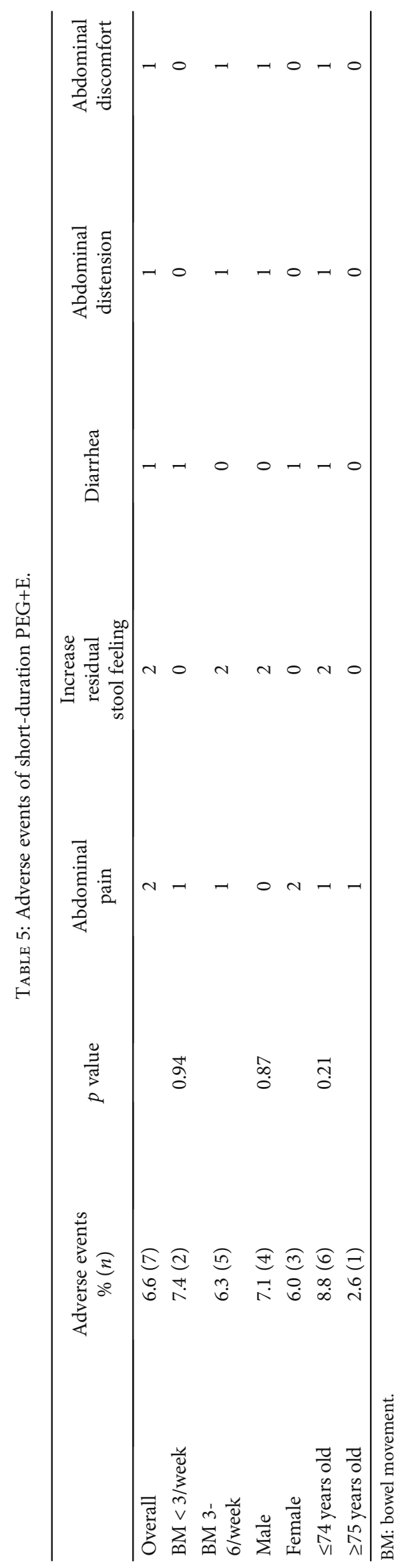


at the first and second weeks were $87.3 \%$ and $80.0 \%$, respectively, which was comparable to that in our study $(90.6 \%)$ [18]. The authors analyzed the rates of complete SBMs, defined as SBMs with a feeling of complete evacuation, and the rates in the first and second weeks were $23.8 \%$ and $37.5 \%$, respectively. We calculated the improvement rate in overall constipation symptoms instead of complete SBMs and found this rate to be $59.4 \%$. This difference was due to the high rate of cases with 3-6 BMs/week, as the improvement rate about symptoms in those cases was higher than in cases with $<3 \mathrm{BMs}$ /week.

In an RCT from France, comparing PEG4000 to lactulose, the case number, rate of females, and mean age in the PEG group were $32,84.3 \%$, and $57 \pm 19$ years old, and the average amount of PEG4000 was $19 \pm 5 \mathrm{~g} /$ day [19]. The rates of improvement in stool frequency from $<3 /$ week, difficulty in defecating, and a straining feeling were $62 \%, 69 \%$, and $37 \%$. These rates were comparable to those in our study, although the ethnicity and rate of females were different to our study.

Another paper also suggested that PEG was not markedly affected by any ethnic factors because it is mostly not absorbed and only increases the water content of stool in a dose-dependent manner [20]. Regarding age, we compared the efficacy in patients $\leq 74$ years old to that in patients $\geq$ 75 years old, noting no significant difference. In children, a systematic review of three studies showed better results with regard to the number of SBMs for PEG than for lactulose [21]. We therefore suggest that $P E G+E$ is effective for increasing the SBM, regardless of age.

Regarding adverse events due to the drug, the rate was $7.5 \%(6 / 80)$ in a previous Japanese study, all of which were mild gastrointestinal disorders, including abdominal pain and diarrhea [18]. The rate in a study from France was $15.7 \%(5 / 32)$, all of which were mild abdominal pain and distention [20]. In addition, the rate in a report from the UK was $9.0 \%$, including abdominal pain in $4.5 \%$ and diarrhea in $4.5 \%$ [17]. The rate in the present study was $6.6 \%$, with no significant differences noted in the baseline number of BMs, gender, or age. We demonstrated the high safety of a small amount of $\mathrm{PEG}+\mathrm{E}$ for chronic constipation.

This study was limited by its retrospective nature and small number of cases. Thus, there was a selection bias about enrolled patients because it was not consecutive and decided by each doctor's decision.

\section{Conclusion}

In more than 100 clinical cases, including elderly and male patients, short-duration and small-amount PEG+E was effective for improving poor colonoscopic BP, SBMs, stool consistency, and symptoms of constipation, regardless of age and gender.

\section{Data Availability}

The patient data used to support the findings of this study are available from the corresponding author upon request. How- ever, some of them are restricted by the institutional review board in the Nishijin Hospital.

\section{Conflicts of Interest}

The authors declare that they have no conflicts of interest.

\section{Acknowledgments}

We would like to extend our appreciation to Dr. Yasutaka Morimoto, Dr. Naoki Wakabayashi, Dr. Kotaro Okuda, Dr. Takashi Okuda, Dr. Akira Tomie, Dr. Kouichi Soga, Dr. Kiyoshi Ogiso, Dr. Daisuke Hasegawa, Dr. Munehiro Kugai, Dr. Takayuki, Motoyoshi, and Dr. Ritsu Yasuda in the Kyoto Improvement of Colonoscopy Seminar (KICS) group as well as the medical members at Molecular Gastroenterology and Hepatology in the Kyoto Prefectural University of Medicine.

\section{References}

[1] A. G. Zauber, S. J. Winawer, M. J. O'Brien et al., "Colonoscopic polypectomy and long-term prevention of colorectal-cancer deaths," The New England Journal of Medicine, vol. 366, no. 8, pp. 687-696, 2012.

[2] M. Alvarez-Gonzalez, J. F.-L. Roux, A. Seoane et al., "Efficacy of a multifactorial strategy for bowel preparation in diabetic patients undergoing colonoscopy: a randomized trial," Endoscopy, vol. 48, no. 11, pp. 1003-1009, 2016.

[3] B. T. Clark, T. Rustagi, and L. Laine, "What level of bowel prep quality requires early repeat colonoscopy: systematic review and meta-analysis of the impact of preparation quality on adenoma detection rate," The American Journal of Gastroenterology, vol. 109, no. 11, pp. 1714-1723, 2014.

[4] S. Mahmood, S. M. Farooqui, and M. F. Madhoun, "Predictors of inadequate bowel preparation for colonoscopy: a systematic review and meta-analysis," European Journal of Gastroenterology \& Hepatology, vol. 30, no. 8, pp. 819-826, 2018.

[5] J. Fang, H. Y. Fu, D. Ma et al., "Constipation, fiber intake and non-compliance contribute to inadequate colonoscopy bowel preparation: a prospective cohort study," Journal of Digestive Diseases, vol. 17, no. 7, pp. 458-463, 2016.

[6] D. W. Lee, J. S. Koo, S. Kang et al., "Association between bowel habits and quality of bowel preparation for colonoscopy," Medicine, vol. 96, no. 29, p. e7319, 2017.

[7] G. Hernández, A. Z. Gimeno-García, and E. Quintero, "Strategies to improve inadequate bowel preparation for colonoscopy," Front Med (Lausanne), vol. 6, p. 245, 2019.

[8] American College of Gastroenterology Chronic Constipation Task Force, "An evidence-based approach to the management of chronic constipation in North America," The American Journal of Gastroenterology, vol. 100, no. S1, pp. S1-S4, 2005.

[9] C. Nyberg, J. Hendel, and O. H. Nielsen, "The safety of osmotically acting cathartics in colonic cleansing," Nature Reviews. Gastroenterology \& Hepatology, vol. 7, no. 10, pp. 557-564, 2010.

[10] A. E. Bharucha, J. H. Pemberton, and G. R. Locke, “American Gastroenterological Association technical review on constipation," Gastroenterology, vol. 144, no. 1, pp. 218-238, 2013.

[11] Research Society for the diagnosis and treatment of chronic constipation, Evidence-based Cliical Practice Guidelines for 
Chronic Constipation, 2017 The Japanese Society of Gastroenterology, Nankodo Co Tokyo, Japan, 2017.

[12] C. A. Aronchick, "Bowel preparation scale," Gastrointestinal Endoscopy, vol. 60, no. 6, pp. 1037-1038, 2004.

[13] D. Drossman, L. Chang, W. D. Chey, J. Kellow, J. Tack, and W. E. Whitehead, Rome IV Functional Gastrointestinal Disorders, Rome Foundation, INC, 4th edition, 2016.

[14] A. Nakajima, M. Seki, S. Taniguchi et al., "Safety and efficacy of elobixibat for chronic constipation: results from a randomised, double-blind, placebo-controlled, phase 3 trial and an openlabel, single-arm, phase 3 trial," The Lancet Gastroenterology \& Hepatology, vol. 3, no. 8, pp. 537-547, 2018.

[15] S. J. Lewis and K. W. Heaton, "Stool form scale as a useful guide to intestinal transit time," Scandinavian Journal of Gastroenterology, vol. 32, no. 9, pp. 920-924, 2009.

[16] N. Yoshida, Y. Naito, T. Murakami et al., "Safety and efficacy of a same-day low-volume 1 L PEG bowel preparation in colonoscopy for the elderly people and people with renal dysfunction," Digestive Diseases and Sciences, vol. 61, no. 11, pp. 32293235, 2016.

[17] R. W. Chapman, V. Stanghellini, M. Geraint, and M. Halphen, "Randomized clinical trial: macrogol/PEG 3350 plus electrolytes for treatment of patients with constipation associated with irritable bowel syndrome," The American Journal of Gastroenterology, vol. 108, no. 9, pp. 1508-1515, 2013.

[18] A. Nakajima, K. Shinbo, A. Oota, and Y. Kinoshita, "Polyethylene glycol 3350 plus electrolytes for chronic constipation: a 2-week, randomized, double-blind, placebo-controlled study with a 52-week open-label extension," Journal of Gastroenterology, vol. 54, no. 9, pp. 792-803, 2019.

[19] Y. Bouhnik, C. Neut, L. Raskine et al., "Prospective, randomized, parallel-group trial to evaluate the effects of lactulose and polyethylene glycol-4000 on colonic flora in chronic idiopathic constipation," Alimentary Pharmacology \& Therapeutics, vol. 19, no. 8, pp. 889-899, 2004.

[20] H. F. Hammer, C. A. S. Ana, L. R. Schiller, and J. S. Fordtran, "Studies of osmotic diarrhea induced in normal subjects by ingestion of polyethylene glycol and lactulose," Journal of Clinical Investigation, vol. 84, no. 4, pp. 1056-1062, 1989.

[21] H. Lee-Robichaud, K. Thomas, J. Morgan, R. L. Nelson, and Cochrane Colorectal Cancer Group, "Lactulose versus polyethylene glycol for chronic constipation," Cochrane Database Systematic Reviews, vol. 7, p. CD007570, 2010. 